\title{
Perancangan Sistem Kontrol Kekeruhan Air Berbasis Website Internet of Things
}

\author{
Nikolaus Toni ${ }^{1}$, Indrastanti R. Widiasari ${ }^{2}$ \\ ${ }^{1,2}$ Universitas Kristen Satya Wacana; Jl. Diponegoro No. 52-60, Salatiga, Kec. Sidorejo, Kota \\ Salatiga, Jawa Tengah 50711, telp (0298) 321212 \\ ${ }^{3}$ Program Studi Teknik Informatika, FTI UKSW, Salatiga \\ e-mail: ${ }^{1}$ laustoni77@gmail.com, ${ }^{2}$ indrastanti@uksw.edu
}

\begin{abstract}
Abstrak
Pada musim penghujan, warga Angan Limau tidak pernah mendapatkan air bersih, karena air langsung masuk ke dalam tandon air. Jika hal ini terjadi terus-menerus, warga sekitar akan mudah terkena penyakit akibat mengkosumsi air yang tidak layak dikonsumsi. Maka dari itu, diperlukan alat yang dapat membantu warga sekitar untuk mengontrol kekeruhan air pada tandon air warga tersebut. Penelitian ini menggunakan metode perancangan sistem kendali kekeruhan air pada penampungan air warga Angan Limau berdasarkan website Internet of Things (IoT). Hasil penelitian didapatkan bahwa sistem kontrol kekeruhan air pada air tandon berbasis website dapat membantu mengontrol kualitas serta tingkat kekeruhan air. Dari pengujian yang dilakukan, komponen sensor kekeruhan berjalan dengan baik dan komponen solenoid valve bekerja sesuai dengan kontrol yang diberikan.
\end{abstract}

Kata kunci-Internet of Things (IoT), Tingkat kekeruhan air, Kualitas Air, Website

\begin{abstract}
During the rainy season, the Angan Limau residents never get clean water, because the water goes directly into the water reservoir. If this happens continuously, residents will be susceptible to disease due to consuming water that is not suitable for consumption. Therefore, a tool is needed that can help residents to control the turbidity of water in the residents' water reservoirs. This research used a water turbidity control system design method, on the water reservoirs of Angan Limau residents based on the Internet of Things (IoT) website. The results showed that the website-based turbidity control system in reservoir water can help control the quality and level of water turbidity. From the tests carried out, the turbidity sensor component runs well and the solenoid valve component works following the control given.
\end{abstract}

Keywords -Internet of Things (IoT), Water turbidity level, Water Quality, Website

\section{PENDAHULUAN}

Internet of Things mengacu pada gagasan umum tentang sesuatu, terutama objek seharihari, yang dapat dibaca, dikenali, dapat ditemukan, dapat dialamatkan melalui perangkat penginderaan informasi maupun dapat dikontrol melalui Internet, terlepas dari alat komunikasi (baik melalui RFID, LAN nirkabel, jaringan area luas, atau cara lain) [1-2]. Sedangkan, [3] menyatakan bahwa Internet of Things (IoT) merupakan sisitem komunikasi yan dapat terhubung dan mengirimkan informasi kepada penerima tanpa campur tangan manusia, atau tidak perlu menambahkan operator untuk mengoperasikan komputer. Internet of Things adalah revolusi baru Internet [4]. Salah satu objek sehari-hari yang dapat diterapkan menggunakan Internet of 
Thing tidak hanya perangkat elektronik, tetapi juga perangkat non elektronik. Objek membuat dirinya dapat dikenali dan mereka memperoleh kecerdasan dengan kemampuan untuk mengaktifkan informasi yang diperoleh, sehingga dapat menyampaikan informasi dan gambaran yang terdapat dalam diri mereka, sehingga mudah dipahami [1-2].

Sistem kontrol merupakan salah satu cara dalam pengelolaan yang tidak akan bisa lepas dari segala aktivitas di kehidupan sehari-hari. Mulai dari barang-barang keluarga seperti dispenser, lemari es dan lain-lain atau berbagai bidang yang termasuk dalam sistem manipulasi pesawat, drone, pengolahan makanan, industri produksi dan lain-lain. Saat ini, perangkat manipulasi dapat digunakan untuk mengontrol kualitas air yang secara signifikan membantu masyarakat dalam mengontrol kualitas air sepanjang musim hujan [5-6].

Penelitian ini dilakukan pada tandon air warga Dusun Angan Limau Kalimantan Barat, yang saat ini belum ada alat sistem kontrol kekeruhan air. Pada musim penghujan warga Angan Limau tidak pernah mendapatkan air bersih, yang diakibatkan air langsung masuk ke dalam tendon. Jika hal ini terjadi terus-menerus, warga sekitar akan mudah terkena penyakit akibat mengkonsumsi air yang tidak layak dikonsumsi. Maka dari itu, diperlukan alat yang dapat membantu warga sekitar untuk mengontrol kekeruhan air pada tandon air warga tersebut. Untuk menjaga kualitas air, maka peneliti akan membuat alat system yang menggunakan sensor turbidity berbasis website Internet of Things (IoT), dengan menggunakan sistem mikrokontroler ATmega328, modul GSM800L, Sensor Turbidity, USB to Serial, Soket Solenoid Valve. Soket Solenoid Valve dimanfaatkan dalam membuka dan menutup aliran air melalui tegangan yang terpasang pada terminal sekrup supaya langsung terhubung ke internet dan terhubung ke website dan Internet of Things (IoT) agar mempermudahkan masyarakat dalam melaksanakan pemantauan dan dapat mengontrol dari website. Website digunakan untuk meng-upload data masuk melalui sensor turbidity dan menampung data seberapa persen banyaknya kekeruhan air terdidektsi yang dianggap tidak layak di konsumsi dan layaknya air dikonsumsi dari alat yang akan dirancang peneliti.

Dari pernyataan di atas, riset yang akan dikerjakan ini, bertujuan agar mampu menciptakan alat yang dapat mengontrol dan mengetahui tingkat kekeruhan air pada tandon air berbasis website dan Internet of Things (IoT), untuk mempermudahkan warga Angan Limau dalam mengontrol kekeruhan air pada tandon air.

\section{METODE PENELITIAN}

\subsection{Kajian Pustaka}

\subsubsection{Penelitian Terdahulu}

Pada riset yang pernah dilakukan pada waktu yang telah lalu, pernah dilakukan kajian yang mengambil tema tentang pembuatan sistem yang dapat mengontrol tingkat kekeruhan air. Sistem ini berbasis pada penggunaan Internet of Things (IoT), salah satu yang dapat digunakan untuk monitoring kekeruhan air PDAM. Sistem ini memanfaatkan teknologi Mikontroller ATMega328, agar lebih mudah dalam penggunaannya teknologi ini dilengkapi dengan sensor fotodiode dan sensor untuk mendeteksi aliran air.

Riset lainnya dengan tujuan untuk mengetahui tingkat kekeruhan air di tandon yang digunakan oleh warga, sistem ini memamfaatkan teknologi berbasis IoT yang menggunakan sensor turbidity (TSD-10) berbasis Internet of Things (IoT). Agar memperoleh informasi yang akurat tetang tingkat kekeruhan air di tandon warga, air yang mengalir disalurkan diantara sumber cahaya dan detector. Cahaya yang digunakan dalam sistem ini diperoleh dari dioda laser yang dipancarkan cahayanya agar mengenai air yang mengalir, jika air yang mengalir diantara cahaya tersebut terdapat banyak partikel yang menjadikan air semakian keruh. Cahaya yang 
dipancarkan oleh dioda laser sebagian akan diteruskan, akan tetapi sebagian besar akan dihamburkan. Alat detektor yang berbentuk fotodioda TSL 250 akan menerima intesnitas cahaya yang dihamburkan, sehingga dapat dketahui tingkat kekeruhah air tersebut [5].

Berdasarkan penelitian sebelumnya yang telah dilakukan diatas, pada penelitian ini penulis merancang suatu sistem kontrol kekeruhan air pada tandon air berbasis Website Internet of Things (IoT), dan penulis menggunakan alat tambahan yang digunakan adalah Kran Selonoid Valve, WeMos D1 R1, Amplifier, Terminal sekrup dan Website. Bertujuan untuk mempermudah Warga Angan Limau dalam mengontrol tingkat kekeruhan air pada tandon air.

Penelitian ini menggunakan metode yang berbasis pada penggunaan rancang bangun yang dapat dugunakan untuk mengetahui tingkat kekeruhan air tandon yang digunakan oleh warga Angan Limau berbasis website Internet of Things (IoT). Sistem kontrol kekeruhan air dapat digunakan untuk mengontrol kekeruhan air agar dapat mengetahui tingkat kekeruhan air. Penelitian ini dilaksanakan pada tandon air Warga Angan Limau, Kalimantan Barat.

\subsubsection{Arduino IDE}

Arduino IDE merupakan salah satu perangkat lunak yang masuk dalam kategori open source, sehingga program ini memungkinkan untuk dapat diunduh secara gratis. Agar program ini dapat dijalankan tentunya board mikrokontroler perlu diberi program. Pada sistem ini digunakan board NodeMCU sehingga untuk dapat digunakan perlu diberikan program pada aplikasi arduino IDE.

\subsubsection{Sensor Turbidity}

Sensor turbidity adalah salah satu pedoman yang dapat digunakan untuk mengukur tingkat kekeruhan yang terkandung dalam air, pada dasarnya untuk mengetahui tingkat kekeruhan yang terkandung dalam air tidak dapat diketahui dengan kasat mata. Oleh sebab itu diperlukan alat bantu yang dapat mengukur tingkat kekeruhan dalam air, salah satu indikasi yang mudah dipahami ialah, bahwa semakin banyak partikel yang terlarut dalam air maka akan semakin tinggi tingkat kekeruhan dalam air. Semakin tinggi tingkat kekeruhan yang terkandung dalam air, diikuti dengan perubahan yang dihasilkan oleh sensor [7]. Sensor yang digunakan memiliki sistem kerja yang mampu menangkap kejadian-kejadian fisik maupun perubahanperubahan kimiawi. Perubahan tersebut kemudian ditransfer menjadi sinyal listrik baik berupa tegangan maupun arus listrik yang dapat mengukur tingkat kekeruhan dalam air.

\subsubsection{WeMos DI RI}

WeMos $d 1$ rl ialah salah satu modul yang yang dimuat dalam board yang fungsinya nya program ini akan mendapatkan hasil yang lebih maksimal ketika digunakan dalam Project yang berbasis dengan konsep IoTd [10]. Keunggulan yang terdapat dalam program WeMos dl rl ialah dapat beroperasi pada suhu tegangan 3,3V, program ini dilengkapi dengan 11 pin digital termasuk di dalamnya spesimen pin yang dapat berfungsi sebagai one-wire PWM, i2c, SPI, yang seluruh programnya berbasis pada micro USB. Selain itu program ini dilengkapi dengan memori flash sebesar 4 Mbyte, dan dimensi modul 34,2 $\mathrm{mm}$ x 25,6mm.

\subsubsection{PHP}

PHP adalah sebuah platform yang menggunakan cript server-facet sebagai bahasa pemrogramannya, program ini dirancang agar dapat digunakan dengan jarak yang jauh, karena sistem ini dimanfaatkan untuk hal-hal yang terkait dengan situs web. Website yang memiliki file dengan extensi file. Php tidak dapat mengakses tanpa adanya web server.

Nugraha memaparkan pendapatnya tentang PHP yang merupakan kepanjangan dari Personal Home Page, adalah program yang tertanam dalam html yang ketika dieksekusi sifatnya menjadi server side. PHP ini termasuk salah satu program yang masuk dalam kategori open 
source produk yang dapat didistribusikan dengan bebas. PHP dapat digunakan dalam berbagai program website seperti Personal Web Server/ PWS, Internet Information Service/ IIS dan Apache Xitami. Program PHP dapat berjalan di sistem yang beraneka ragam, seperti sistem Microsoft Windows seluruh versi, sistem Linux dan sistem Max OS

\subsubsection{Database}

Database (Basis Data) adalah kumpulan dari berbagai data yang berbentuk arsip atau file yang saling berhubungan antara satu dengan yang lainnya, sehingga terlahir pengelolaan spesifik yang dapat menampilkan data baru maupun informasi. Basis data dapat didefinisikan sebagai karakteristik yang termuat dalam data tersebut, batasan-batasan data yang akan disimpan, dan struktur dalam data tersebut.

\subsubsection{MySQL}

MySQL merupakan salah satu database yang dapat mengelola berbagai jenis data yang yang pengoperasiannya menggunakan perintah dasar Structured Query Language/ SQL. Pengelolaan database yang digunakan dalam $M y S Q L$ telah digunakan lebih dari 6.000 .000 pengguna di seluruh dunia, MySQL merupakan salah satu program yang masuk dalam kriteria open source dengan memiliki dua lisensi. Pertama ialah software yang penggunaannya bebas, kedua ialah perangkat lunak yang kepemilikan dan penggunaannya terbatas. MySQL AB meluncurkan program dengan nama $M y S Q L$ yang dapat diakses secara gratis oleh siapa saja yang lisensinya di bawah naungan GNU/ General Public Licencse (GPL). Apabila pengguna program $M y S Q L$ tidak cocok dan tidak sesuai dengan program gratis yang yang dikeluarkan oleh General Public Licencese (GPL).

\subsection{Metode Penelitian}

Metode penelitian merupakan tahapan yang harus dilalui yang dapat berupa pengamatan atau tahap pelaksanaan yang dilakukan secara ilmiah untuk menyusun, menganalisis dan menyimpulkan data sehingga dapat digunakan pada pengembangan suatu sistem.

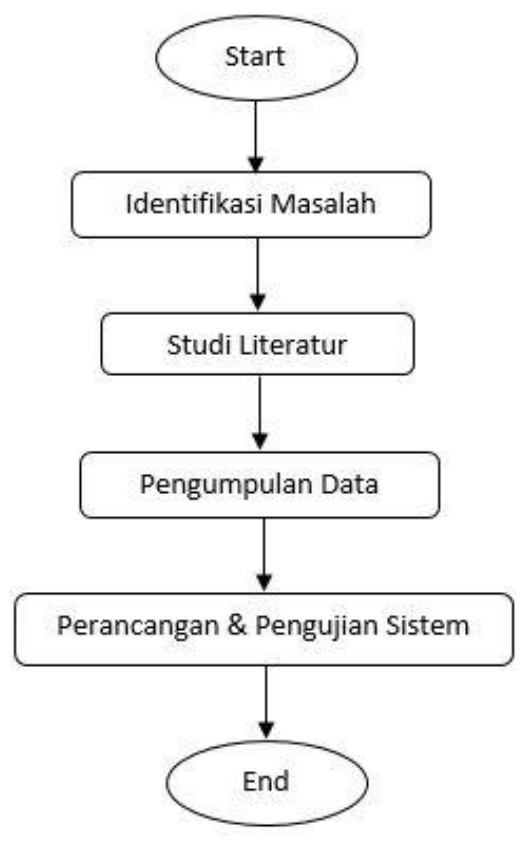

Gambar 1. Tahap Penelitian 
Pada gambar 1 diatas merupakan langkah-langkah awal dalam melakukan perancangan sistem kontrol kekeruhan air berbasis website Internet of Things (IoT). Berikut adalah tahapan yang harus dilakukan sebelum membangun suatu sistem:

1. Identifikasi masalah, adalah langkah untuk pengidentifikasi masalah yang terkit dalam penelitian ini. Terdapat permasalahan pada penelitian ini adalah kesulitan pada saat minta izin kepada pihak dusun yang keterbatasan dalam memahami teknologi.

2. Studi literatur, adalah langkah untuk melakukan pengumpulan data dari penelitian sebelumnya, seperti: buku, jurnal dan data di internet lainnya untuk mendukung kelancaran pada penelitian ini.

3. Pengumpulan data merupakan tahapan yang dilakukan untuk mendapatkan data yang berhubungan dengan penelitian yang akan dikaji, metode pengumpulan data pada riset ini menggunakan metode observasi dan wawancara. Sumber data ini termasuk dalam kategori Sumber data primer yang diperoleh secara langsung dengan jalan tanya jawab pada Bapak Domianus Young selaku kepala Dusun Angan Limau dan membagi kuesioner kepada warga setempat.

4. Perancangan data untuk menguji sistem, tahapan ini merupakan langkah yang dilakukan agar melahirkan sebuah rancangan yang dapat digunakan untuk menguji sistem yang dapat mengukur keakuratan pada sistem kontrol kekeruhan air. Sistem ini menggunakan metode pengembangan Prototype.

\subsubsection{Metode Pengembangan System}

Metode yang digunakan dalam tahapan ini, difokuskan dengan menggunakan metode prototype, pada metode ini berupa perangkat lunak yang berbentuk fisik yang digunakan untuk mendefinisikan persyaratan desain. Prototipe digunakan oleh pengembang untuk perencanaan dan analisis. hingga pada tahap uji coba yang dilakukan secara waktu yang bersamaan dengan proses pengembangan sistem.

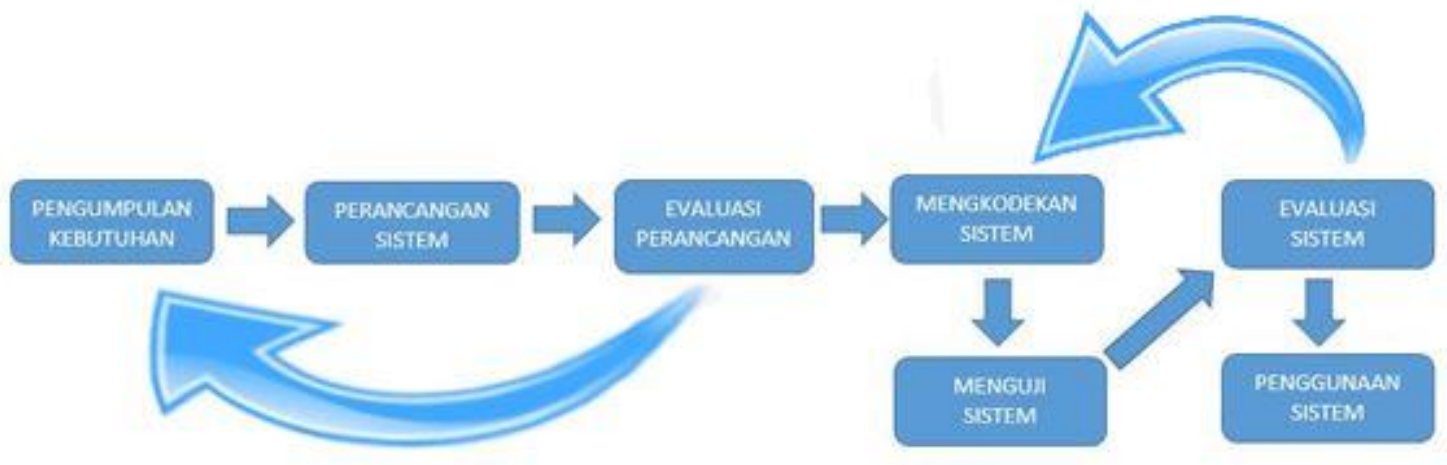

Gambar 2. Tahap Penelitian

Pada tahapan penelitian menjelaskan mengenai Perancangan Sistem Kontrol Kekeruhan Air Berbasis Website Internet of Things (IoT), yang disajikan dalam gambar 2 di atas dengan penjelasan sebagai berikut:

1. Tahapan pengumpulan kebutuhan, merupakan salah satu cara untuk mendapatkan semua kebutuhan perancangan sistem yang akan dibangun dengan cara melakukan wawancara pada pihak yang mengizinkan tempat penelitian salah satunya Kepala Dusun Angan Limau agar sistem yang dibangun dapat lebih efesien.

2. Perancangan sistem, merupakan tahapan awal dalam membuat sistem dan berfokus pada penyajian sistem yang akan dibangun. 
3. Evaluasi perancangan, merupakan salah satu cara untuk mengetahui apakah rancangan yang digunakan telah sesuai dengan harapan. Jika belum sesuai dengan harapan yang diinginkan maka akan kembali ke pada tahapan pengumpulan kebutuhan guna untuk memenuhi kekurangan kebutuhan.

4. Mengkodekan sistem, merupakan salah satu perancangan yang telah disetujui dan akan diubah ke dalam bahasa pemograman.

5. Menguji sistem ialah proses uji coba pada perangkat lunak maupun perangkat keras yang telah di rancang. Kegiatan ini dilakukan agar dapat mengetahui apakah sistem yang telah dibuat sesuai dengan harapan yang diinginkan kan atau tidak.

6. Evaluasi sistem merupakan tahapan yang dilakukan ketika perangkat lunak yang telah digunakan menghasilkan kriteria sesuai dengan yang diharapkan atau tidak. Jika hasil yang dikeluarkan dalam sistem tersebut tidak sesuai dengan keinginan, maka akan dikembalikan Pada tahapan pengkodean. Sehingga kegiatan evaluasi dapat terlaksana dengan baik.

7. Penggunaan sistem merupakan tahapan yang dilakukan ketika perangkat yang di rancang telah diuji dan sesuai dengan harapan sehingga sistem tersebut telah layak digunakan.

\subsubsection{Arsitektur system, ialah model konseptual yang mendefinisikan}

Struktur, perilaku dari suatu sistem. Tujuan untuk merancang struktur ini untuk memenuhi kebutuhan pengguna [8].

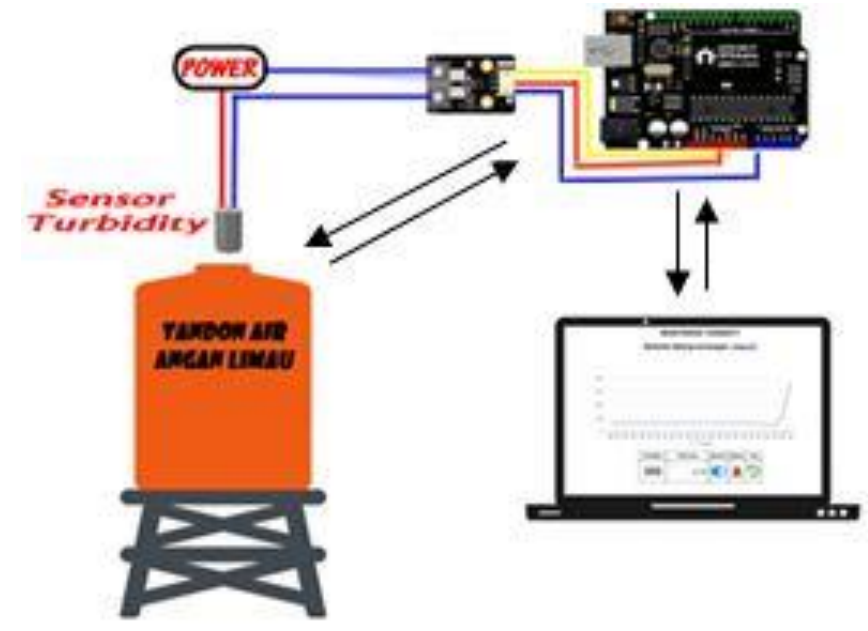

Gambar 3. Arsitektur Sistem

Pada gambar 3 tersebut, adalah tahap perancangan arsitektur dari sistem kontrol kekeruhan air pada tandon air berbasis website Internet of Things (IoT), sebagai salah satu panduan agar mempermudah pengguna dalam menggunakan dan agar mudah dipahami alur dari sistem yang dibangun. Sedangkan, [8] ketika user melakukan perintah maka perintah akan diproses di dalam komputer, laptop maupun smartphone, untuk melakukan perintah tersebut maka harus tersambung dengan jaringan internet terlebih dahulu.

Sistem kontrol kekeruhan air ini digunakan untuk mendeteksi jika didalam tandon air terdapat partikel-partikel yang dimana sensor akan mengirimkan notifikasi ke website berupa suara atau alarm yang terpasang bertujuan untuk mengetahui didalam tandon air sudah tidak layak dikonsumsi dan proses pembuangan air dalam tandon atau kran selonoid valve yang telah terpasang dengan otomatis terbuka sebagai saluran atau pralon pembuangan air. 


\subsubsection{Use Case Diagram}

Program ini merupakan salah satu terobosan yang dapat digunakan untuk menampilkan sistem dengan masukan masing-masing fungsi yang dibutuhkan untuk bekerja sesuai alur hingga dapat menghungkan aktor dalam sistem website yang dibangun.

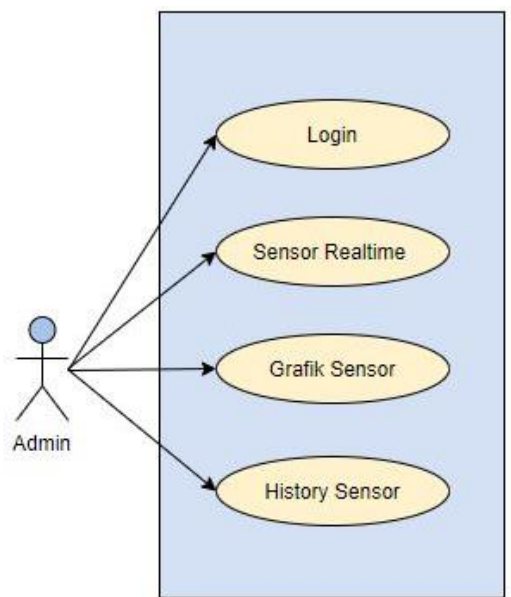

Gambar 4. Use Case Diagram

Gambar yang ditunjukkan pada nomor 4 tersebut memberikan informasi bahwa dalam beberapa sistem yang terdapat di program tersebut, dapat dikelola atau diatur oleh seorang admin yang mengakses website yang tersambung pada sensor kekeruhan air. Terlihat admin melakukan akses dalam website ini yaitu (Login, Sensor Realtime, Grafik Sensor, History Sensor) secara otomatis terhubung pada sensor turbidity yang telah terpasang pada tandon air.

\subsubsection{Activity Diagram}

Dalam bagian ini menjelaskan terkait dengan activity diagram yaitu rancangan untuk membuat alur perencanaan dan akan digunakan untuk membangun suatu sistem kontrol kekeruhan air pada tandon air warga Angan Limau.

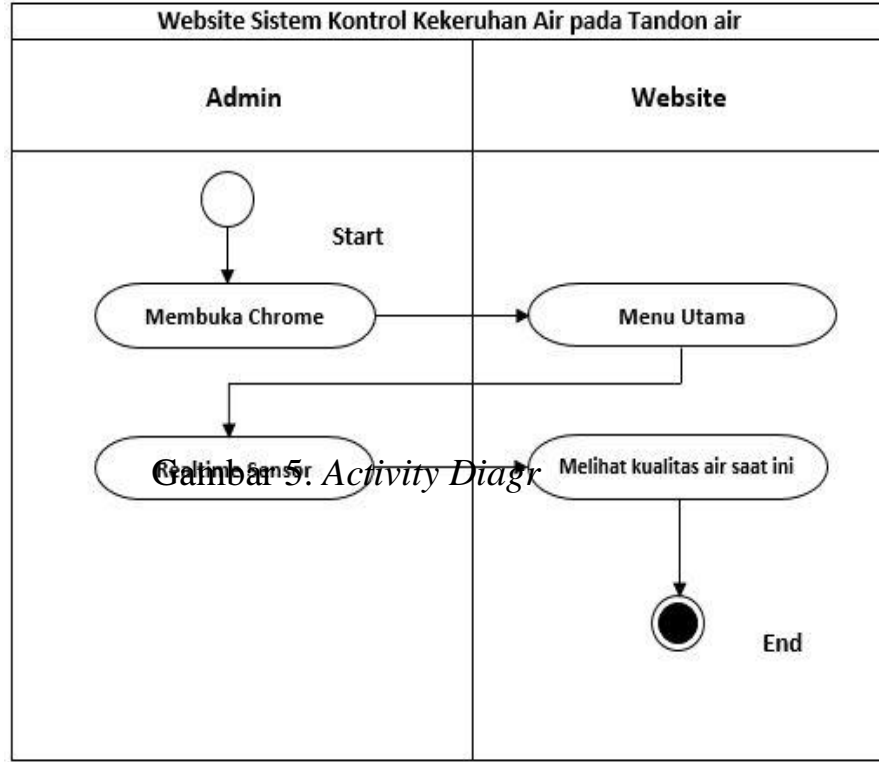

Gambar 5. Activity Diagram 
Pada gambar 5 diatas merupakan langkah awal admin melakukan proses untuk masuk kedalam website. Untuk ke menu utama atau melakukan login admin harus membuka google chorme terlebih dahulu supaya dapat terakses ke dalam website tersebut.

\subsubsection{Diagram Jenjang Sistem}

Diagram Jenjang sistem yang digunakan untuk menggambarkan rangkaian sistem dan langkah-langkah yang harus dilakukan oleh admin dari sebuah website.

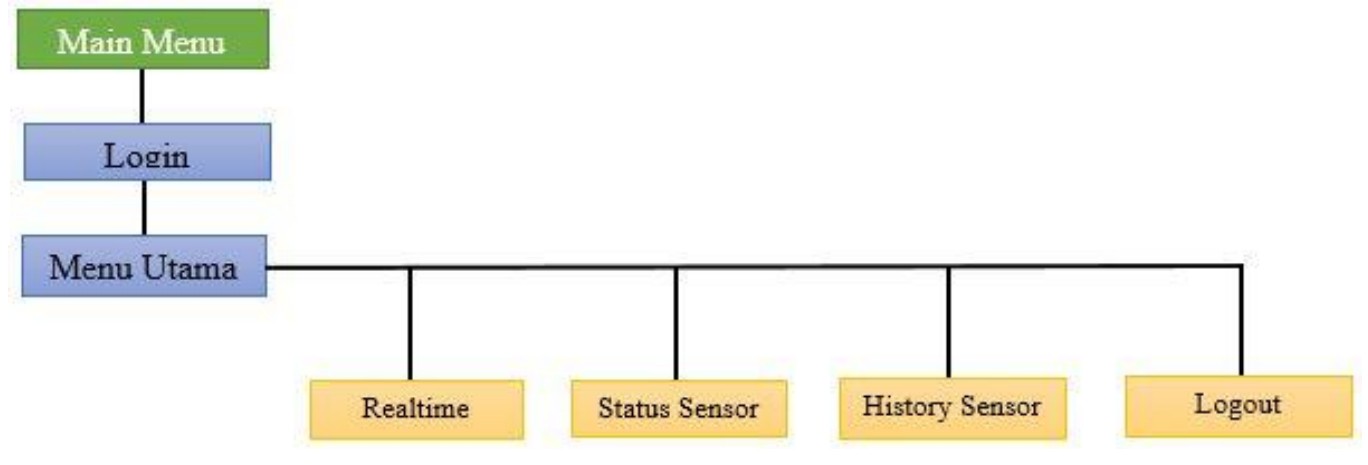

Gambar 6. Diagram Jenjang Sistem

Pada gambar 6 diatas merupakan salah satu ilustrasi dari website yang menunjukkan bahwa proses admin untuk masuk ke dalam website. Diagram jenjang sistem berfungsi untuk memberikan gambaran yang ditail dari use case.

\subsubsection{Rangkaian Sistem}

Perancangan sistem merupakan salah satu alur dalam membangun suatu sistem yang bertujuan agar dapat menjadi perantara hubungan antara dua perangkat, perangkat lunak dengan perangkat keras, yaitu antara sensor turbidity dan website sehingga mencapai suatu tujuan yang sama. Sensor turbidity akan membaca partikel-partikel yang ada di dalam air kemudian mengirimkan hasil sensor ke dalam website dan data disimpan pada database yang berupa hasil akhir yang dihasilkan sensor turbidity melalui sebuah jaringan wemos d1 r1.

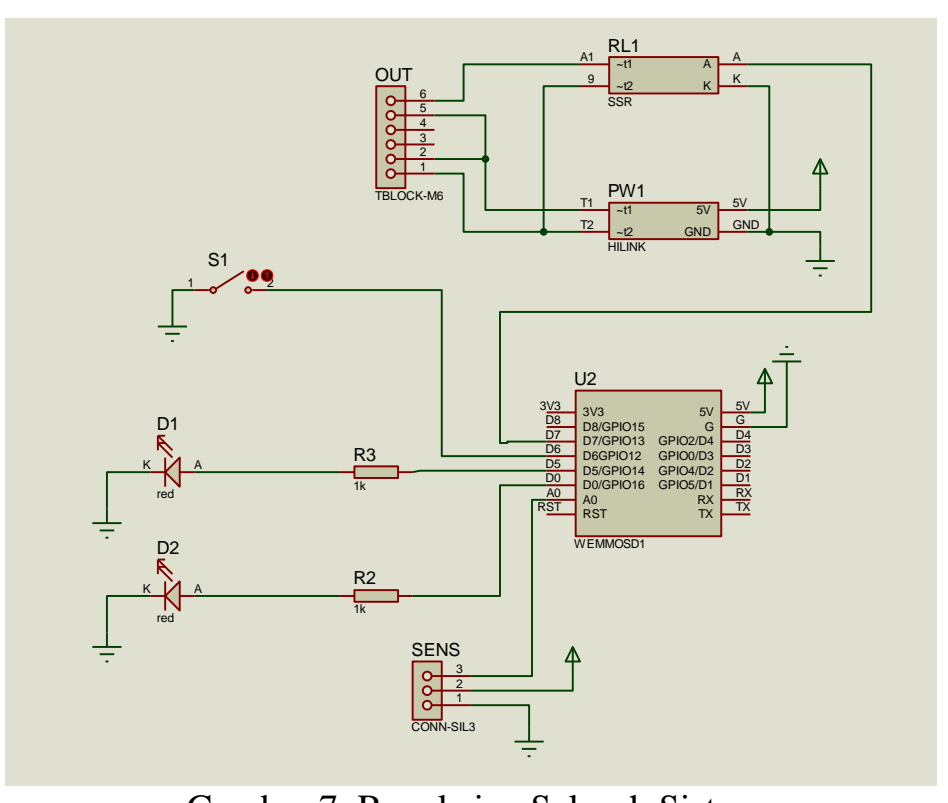

Gambar 7. Rangkaian Seluruh Sistem 
Pada gambar 7 diatas yang menunjukkan sebuah rangkaian dari proses membuatan sistem sehingga rangkaian tersebut dapat di wujudkan dalam sebuah perangkat lunak maupun ke dalam perangkat keras, yaitu: Sesnor kekeruhan air berbasis website Internet of Things (IoT).

\section{HASIL DAN PEMBAHASAN}

\subsection{Tampilan Website}

Website memiliki sebuah tampilan yang dapat memberikan suatu tampilan optis yang berada di dalam sebuah website untuk menghubungkan antara sistem dengan pengguna. Sebagai bentuk dari perancangan, hasil yang telah dicapai merupakan sebuah website sistem kontrol kekeruhan air berbasis website Internet of Things (IoT).

Tabel 1. Tampilan Website dan Database

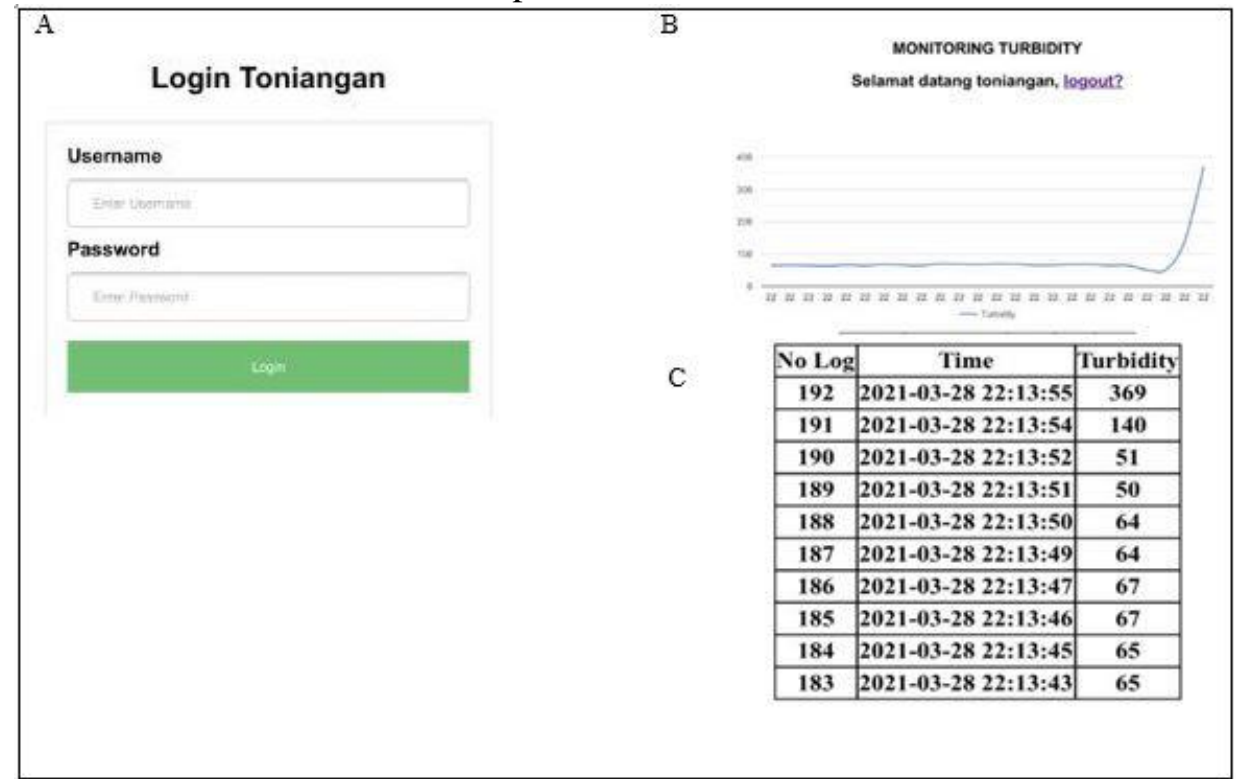

Gambar a merupakan halaman yang menampilkan login memuat terkait username dan password yang telah tersimpan dalam database, agar dapat memasuki website yang dituju [9]. Gambar $b$ adalah sebuah tampilan yang menampilkan halaman utama atau yang sering disebut dengan beranda, yang mana apabila pihak admin berhasil melakukan login akan memasuki halaman beranda ini [9]. Beranda akan memberikan tampilan beberapa menu lainnya, seperti menu Grafik Sensor, Turbidity Realtime Sensor, Set Point, Manual, Status dan menu Log. Grafik sensor menunjukkan bahwa hasil atau suatu partikel yang terdeteksi oleh sensor turbidity maka yang disebut grafik akan bergerak sesuai situasi sensor turbidity. Gambar $c$ merupakan menu $\log$ atau menu riwayat yang berfungsi menampilkan hasil yang diperoleh atau terekam sensor turbidity kemudian akan di input ke dalam menu log dan diolah menjadi sebuah data. Data yang dibaca oleh sensor turbidity berjalan secara realtime, sehingga data terperinci dengan otomatis dan hasil data yang diperoleh dari sensor turbidity yang kemudian akan dicetak kedalam excel melalui website berupa hasil data akhir. 


\subsection{Kode Program Website}

Tabel 2. Kode Program Website

\begin{tabular}{|c|c|}
\hline 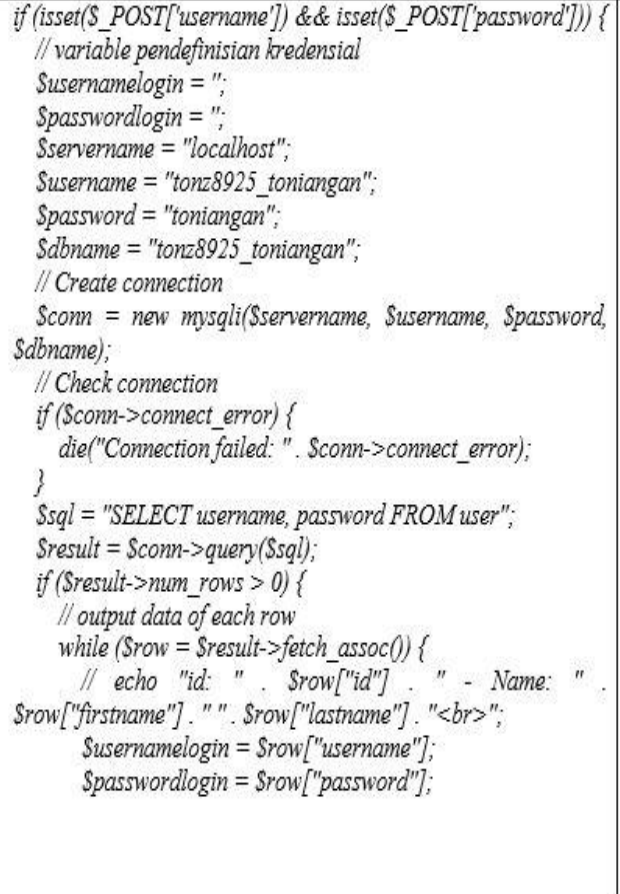 & 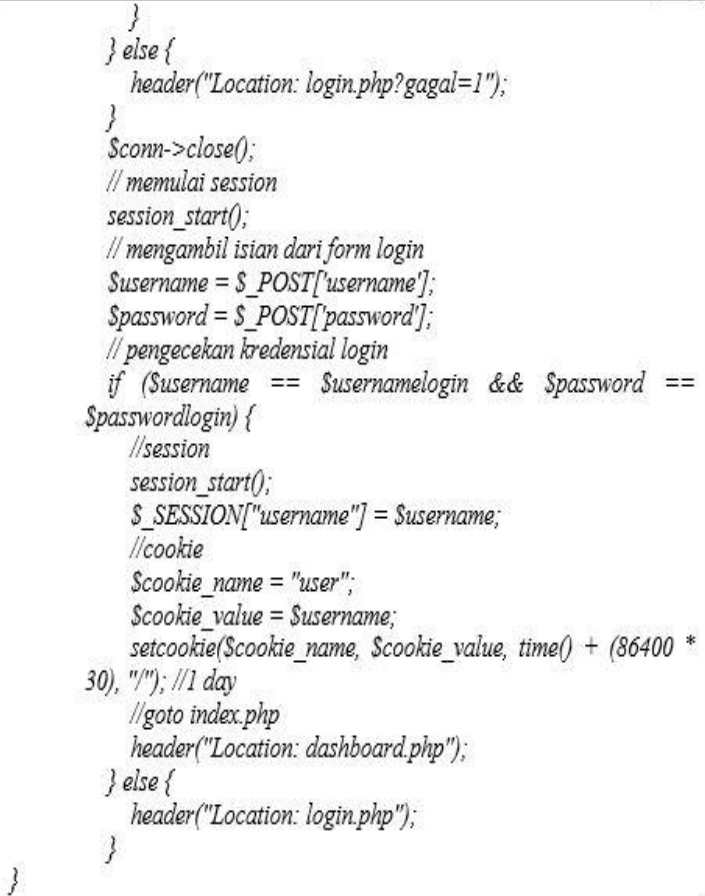 \\
\hline
\end{tabular}

Pada tabel 2 diatas merupakan kode program website yang dibuat menggunakan $P H P$ $M y S Q L$, memiliki peran dan fungsi dalam membuat struktur dalam website yang berguna sesuai dengan harapan pengembang. Website ini telah berhasil terhubung sempurna dengan sensor turbidity dan dapat memperoleh hasil berupa data seperti pada gambar $c$ yaitu: menu $\log$.

\subsection{Kode Program Arduino}

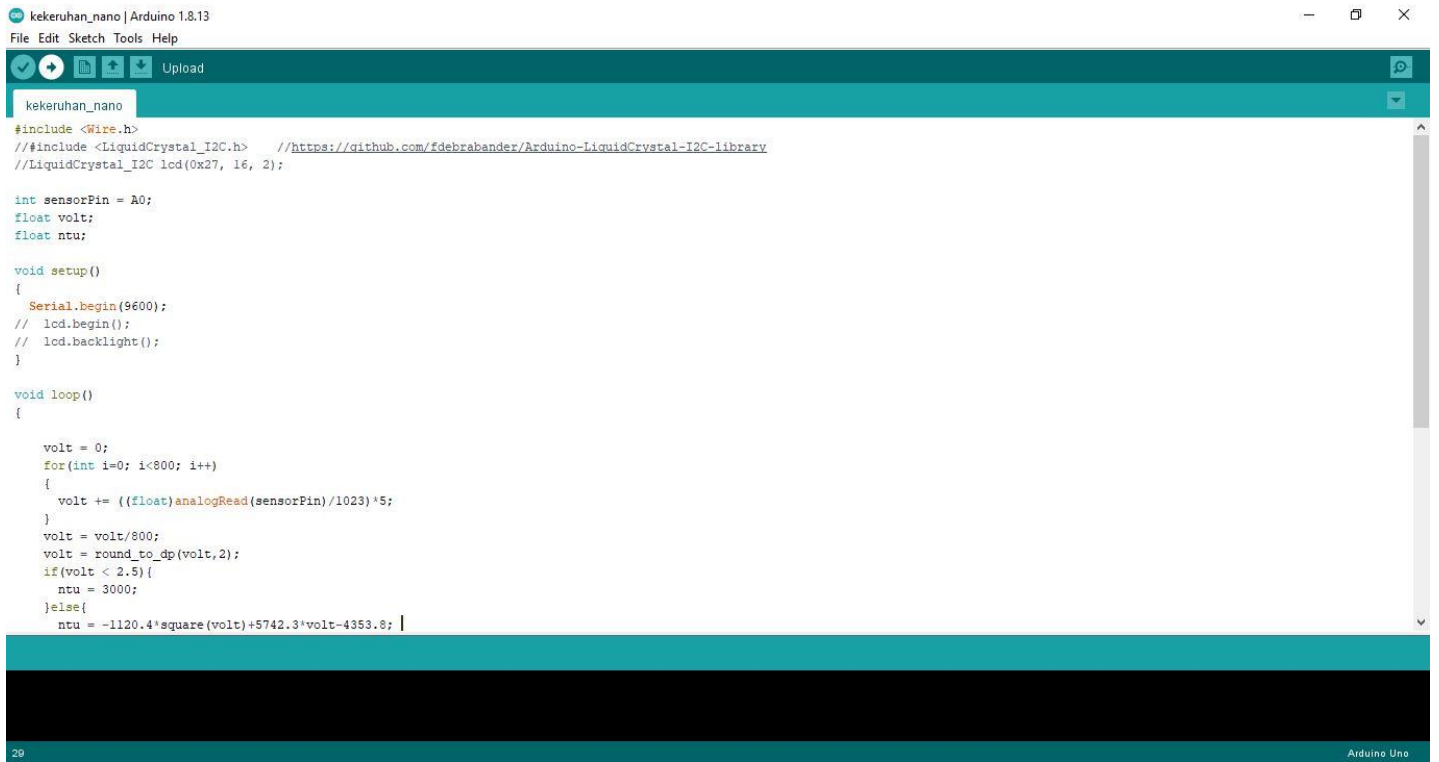

Gambar 8. Kode Program Arduino 
Pada gambar 8 diatas merupakan tampilan program untuk mengaktifkan pin yang ada pada amplifier turbidity, dimana hal tersebut perlu diberi program agar dapat terhubung dengan HiLink step down atau untuk mengubah $220 \mathrm{AC}$ ke 5v.

\subsection{Pengujian Sistem}

Tahapan pengujian sistem dapat di lihat pada gambar $c$ diatas yang menunjukkan dari awal pengujian sistem, kualitas air dibawah ketentuan NTU atau diangka standar 50 NTU sehingga hasil diperoleh 369 NTU dengan kualitas air diatas standar atau tidak layak dikonsumsi dan hasil data akan dikirim ke database dalam website yang telah dihubungkan ke sensor turbidity melalui jaringan WeMos d1 r1.

Tabel 4. Pengujian Sistem Kontrol Kekeruhan Air pada Tandon Air

\begin{tabular}{|c|l|l|c|}
\hline No & \multicolumn{1}{|c|}{$\begin{array}{c}\text { Pengujian } \\
\text { Sistem }\end{array}$} & \multicolumn{1}{|c|}{ Hasil Uji Coba } & Status \\
\hline 1 & Menu Login & Sukses melakukan Login ke dalam website & Valid \\
\hline 2 & $\begin{array}{l}\text { Menu Grafik } \\
\text { Sensor }\end{array}$ & $\begin{array}{l}\text { Grafik sensor bergerak dengan baik sesuai } \\
\text { dengan hasil sensor turbidity }\end{array}$ & Valid \\
\hline 3 & $\begin{array}{l}\text { Menu Realtime } \\
\text { Sensor }\end{array}$ & $\begin{array}{l}\text { Sukses melakukan deteksi kekeruhan air di } \\
\text { dalam tandon air }\end{array}$ & Valid \\
\hline 4 & Alarm & $\begin{array}{l}\text { Memberitahu berupa bunyi ketika sensor } \\
\text { turbidity mendeteksi kekeruhan dalam tandon } \\
\text { air }\end{array}$ & Valid \\
\hline 5 & Menu Log & $\begin{array}{l}\text { Sukses merekap data sesuai hasil deteksi } \\
\text { sensor turbidity }\end{array}$ & Valid \\
\hline
\end{tabular}

Pada tabel 4 diatas menunjukkan bahwa pengujian sistem yang sudah sesuai dengan harapan peneliti dari awal, maka perancangan atau sistem ini sudah layak dipasang dalam tandon air Warga Angan Limau yang sangat membutuhkan sistem kontrol kekeruhan air seperti perancangan yang telah dibuat oleh peneliti. Terdapat beberapa jawaban atau tanggapan dari warga angan limau terkait Sistem Kontrol Kekeruhan Air Berbasis Website Internet of Things yang diberikan peneliti melalui kuesioner. berikut adalah jawaban dari 20 orang warga angan limau menjawab 8 pertanyaan yang tersedia dalam kuesioner yang telah dibagikan.

Berikut adalah tata cara penilaian:

$\begin{array}{llll}\text { - Sangat Puas } & =5 & \text { - Tidak Puas } & =2 \\ \text { - } \quad \text { Puas } & =4 & \text { - Sangat Tidak Puas } & =1 \\ \text { - Cukup Puas } & =3 & & \end{array}$


Tabel 5. Presentase Tingkat Kepuasan

\begin{tabular}{|c|c|c|c|c|c|c|c|}
\hline \multirow{2}{*}{ No } & \multirow{2}{*}{ Pertanyaan } & \multicolumn{5}{|c|}{ Penilaian } & \multirow{2}{*}{$\begin{array}{c}\% \\
\text { Puas }\end{array}$} \\
\hline & & 1 & 2 & 3 & 4 & 5 & \\
\hline 1 & $\begin{array}{l}\text { Seberapa puas anda dengan adanya sistem } \\
\text { kontrol kekeruhan air yang telah dibangun? }\end{array}$ & & & 5 & 2 & $\begin{array}{l}1 \\
3\end{array}$ & 75 \\
\hline 2 & $\begin{array}{l}\text { Apakah anda setuju jika sistem ini dipasang di } \\
\text { dalam tandon air warga angan limau? }\end{array}$ & & & 5 & 5 & $\begin{array}{l}1 \\
0\end{array}$ & 75 \\
\hline 3 & $\begin{array}{l}\text { Apakah anda puas dengan tampilan website } \\
\text { sistem kontrol kekeruhan air berbasis website } \\
\text { Internet of Things? }\end{array}$ & & & 8 & 7 & 5 & 60 \\
\hline 4 & $\begin{array}{l}\text { Dengan adanya sistem ini apakah dapat } \\
\text { membantu anda dalam mengontrol air yang ada } \\
\text { dalam tandon? }\end{array}$ & & & 4 & 8 & 8 & 80 \\
\hline 5 & $\begin{array}{l}\text { Apakah sistem kontrol kekeruhan air berbasis } \\
\text { website Internet of Things sangat dibutuhkan? }\end{array}$ & & & 1 & 3 & $\begin{array}{l}1 \\
6\end{array}$ & 95 \\
\hline 6 & $\begin{array}{l}\text { Apakah struktur menu dalam website yang } \\
\text { disajikan mudah dipahami? }\end{array}$ & & 7 & 5 & 3 & 5 & 40 \\
\hline 7 & $\begin{array}{l}\text { Apakah anda memahami cara kerja sistem } \\
\text { kontrol kekeruhan air berbasis website Internet } \\
\text { of Things? }\end{array}$ & & 5 & 2 & 5 & 8 & 65 \\
\hline 8 & $\begin{array}{l}\text { Seberapa puas anda dengan warna desain } \\
\text { website yang dibangun? }\end{array}$ & & & 5 & 8 & 7 & 75 \\
\hline
\end{tabular}

Pada tabel 5 diatas merupakan data hasil jawaban dari 20 orang warga Angan Limau yang telah mengisi kuesioner dalam bentuk skala Likert. Skala Likert tersebut digunakan untuk menghitung presentase dari setiap pertanyaan yang ada pada kuesioner. Peneliti dapat mengetahui seberapa jumlah dari seluruh para responden dengan menggunakan persentase, sebagaimana rumus berikut ini:

$$
\begin{array}{ll}
f & \begin{array}{l}
\text { Keterangan dari beberapa simbol tersebut yaitu: } \\
n
\end{array} \quad \begin{array}{l}
p: \text { hasil presentase yang dicari } \\
f: \text { frekuensi yang diperoleh dari masing-masing jawaban angket } \\
n: \text { jumlah dari skor ideal } \\
100: \text { bilangan yang telah ditetapkan }
\end{array}
\end{array}
$$

Berdasarkan hasil analisis data kuesioner hasil yang diperoleh adalah sebegai barikut: $75 \%$ responden menyatakan puas dengan adanya sistem kontrol kekeruhan air yang telah dibangun, $75 \%$ responden menyatakan setuju jika sistem ini dipasang di dalam tandon air, $60 \%$ responden menyatakan puas dengan tampilan website sistem kontrol kekeruhan air yang berbasis website IoT, $80 \%$ responden meyatakan sistem kontrol kekeruhan air membantu mengontrol air dalam tandon, 95\% responden menyatakan sistem kontrol kekeruhan air berbasis website IoT sangat di butuhkan, $40 \%$ responden menyatakan struktur menu dalam website sistem kontrol kekeruhan air mudah dipahami, 65\% menyatakan responden menyatakan memahami cara kerja sistem kontrol kekeruhan air berbasia website $I o T$, dan $75 \%$ responden menyatakan puas dengan warna desain website yang dibangun. 
Tabel 6. Skala Tingkat Kepuasan

\begin{tabular}{|l|l|c|c|}
\hline \multicolumn{4}{|c|}{ Skala Reting Kepuasan Pengguna } \\
\hline \multicolumn{1}{|c|}{ Kategori } & Skala & Frekuensi & $\%$ \\
\hline Sangat Baik & $61-100$ & 6 & 75 \\
\hline Baik & $46-60$ & 1 & 12,5 \\
\hline Cukup Baik & $31-45$ & 1 & 12,5 \\
\hline Kurang Baik & $16-30$ & 0 & 0 \\
\hline Sangat Tidak Baik & $0-15$ & 0 & 0 \\
\hline
\end{tabular}

Pada tabel 6 diatas adalah hasil analisis persentase tingkat kepuasan responden. Maka dapat diperoleh hasil gambaran reting kepuasan responden dari 8 item pertanyaan, sebanyak 6 item pertanyaan atau $75 \%$ berada pada kategori kepuasan responden sangat baik,

sebanayk 1 pertanyaan atau 12,5\% berada pada kategori kepuasan responden baik, dan sebanyak 1 pertanaayan atau $12,5 \%$ berada pada kategori kepuasan responden cukup baik.

\section{KESIMPULAN}

Dapat disimpulkan bahwa dengan adanya sistem kontrol kekeruhan air pada tandon air Warga Angan Limau berbasis website dapat membantu dan mempermudah warga dalam mengontrol tingkat kekeruhan air pada tandon air tanpa harus datang kelokasi tandon tersebut. Dari pengujian yang dilakukan untuk komponen sensor kekeruhan berjalan dengan baik. Pengujian komponen solenoid valve bekerja sesuai dengan kontrol yang diberikan.

\section{SARAN}

Saran dari penulis antara lain: 1) menambahkan fitu-fitur dalam website, sehingga website tampak lebih menarik; 2) menambahkan menu-menu pada website, sehingga tidak membingungkan bagi pengguna ke depannya.

\section{DAFTAR PUSTAKA}

[1] Fantana, N.L., Riedel, T., Schlick, J., \& Ferber, S. 2013, Internet of Things: Converging Technologies for Smart Environments and Integrated Ecosystems, Aalborg Denmark: River Publishers.

[2] Fantana, N.L., Riedel, T., Schlick, J., \& Ferber, S. 2013, Internet of Things-From Research and Innovation to Market Deployment, Aalborg Denmark: River Publishers,

[3] Burange, A.W., \& Misalkar, H.D. 2015, Review of Internet of Things in Development of Smart Cities with Data Management \& Privacy.

[4] Patel, K.K., \& Patel, S.M. 2016, Internet of Things-IOT: Definition, Characteristics, Architecture, Enabling Technologies, Application \& Future Challenges. IJESC., No.5, Vol.6, Hal. 6122-6131, 2016 
[5] Sasmoko, D., Rasminto, H., \& Rahmadani, A. 2019, Rancang Bangun Sistem Monitoring Kekeruhan Air Berbasis IoT pada Tandon Air Warga, Jurnal Informatika Upgris., No.1, Vol. 5, Hal. 25-34.

[6] A.E.A. Septyaningrum \& W.D. Kurniawan. Analisa Sistem Pengendalan dan Monitoring Tingkat Kekeruhan Tandon Air Berbasis Arduino Uno dan Internet of Things, JPTM., No. 2, Vol. 10, Hal. 26 - 32, 2021.

[7] Hidayat, R. N. (2021). Perancangan Sistem Deteksi Kekeruhan Air pada Akuarium Ikan Arwana Berbasis IoT. KONSTELASI: Konvergensi Teknologi dan Sistem Informasi, 1(2), 391-401.

[8] Mulyono, T., \& Saian, P. O. N. 2021, Perancangan Sistem Aplikasi Tracking Pendukung Touring Secara Real Time Menggunakan Firebase Berbasis Android (Studi Kasus Komunitas Motor Trigramyama Salatiga).

[9] JATISI (Jurnal Teknik Informatika dan Sistem Informasi), 8(2), 450-464.

[10] Noor, A., Supriyanto, A., \& Rhomadhona, H. 2019, Aplikasi Pendeteksi Kualitas Air Menggunakan Turbidity Sensor dan Arduino Berbasis Web Mobile. Jurnal CoreIT: Jurnal Hasil Penelitian Ilmu Komputer dan Teknologi Informasi, 5(1), 13-18.

[11] Nurdianto, A. 2018, Rancang Bangun Sistem Peringatan Dini Banjir (Early Warning System) Terintegrasi Internet of Things, Jurnal Online Mahasiswa (JOM) Bidang Teknik Elektro, 1(1). 